Gut, 1961, 2, 370

\title{
The first recorded case of Whipple's disease?
}

\author{
A. D. MORGAN
}

\author{
From Westminster Hospital, London
}

It is more than half a century since Whipple described a rare form of intestinal lipodystrophy, 'a hitherto undescribed disease characterized anatomically by deposits of fat and fatty acids in the intestinal and mesenteric lymphatic tissues' (Whipple, 1907). Some idea of the rarity of the condition may be gained from the fact that it was not until 1936 that the next acceptable case was published. The first generally recognized British case appeared only in 1938, under the title of 'mesenteric chyladenectasis', with no reference to Whipple's article (Glynn and Rosenheim, 1938).

It was of some historical interest, therefore, to discover a specimen of Whipple's disease in the pathological museum at Westminster Medical School, and to find that the case had been recorded in British medical literature some 12 years before Whipple published his paper.

It was during a recent reorganization of the gut section in the Westminster museum that an old specimen came under review. This was a U-shaped strip of tissue, gray with age, and with a finely papillated surface. It was labelled 'lymphangiectasis of the stomach', and the museum catalogue simply recorded that the patient was a man who had suffered from intermittent attacks of diarrhoea and vomiting in 1894, and died of exhaustion within a few months.

Closer inspection of the specimen revealed that this was not a stomach but a duodenum mounted at right angles to its normal anatomical position. It then occurred to me that this might be a case of Whipple's disease, and microscopic sections were at once prepared from the bowel and from an attached lymph node. These showed the presence of fat and mucoproteins in the intestinal villi and lymph-node sinuses, strong confirmatory evidence of the presumed diagnosis.

Reference to the post-mortem records of 1894 revealed, together with the necropsy report, a short medical history of the case, and there was a footnote to the effect that the case had been reported by Dr. (later Sir William) Allchin and Dr. R. G. Hebb in the Transactions of the Pathological Society of London (Allchin and Hebb, 1895).

The patient was a policeman named Frederick $J$. Adams and he was aged 38 at the time of his death.
For three months he had been treated at home for diarrhoea and wasting, which was thought to be due to malignant disease. Before this he had been perfectly healthy. Following treatment for diarrhoea he improved sufficiently to be able to return to work, but 24 hours later the diarrhoea recurred, accompanied by vomiting; and he was admitted to Westminster Hospital (in those days in Broad Sanctuary facing the Abbey) on 22 August 1894 and was placed under the care of Dr. Allchin.

The clinical data are scanty. He was 'blue and collapsed' on admission; the vomit was dark green and contained numerous white flecks; the stools had a fluid, 'pea-soupy' appearance and contained large amounts of some oily substance. The urine contained bile but no albumin. Following admission he 'gradually sank' and died within 24 hours.

The necropsy was performed by Dr. Hebb. There were no external abnormalities. The proximal half of the small intestine was distended and its mucous membrane was purple and swollen but not ulcerated. In the author's words, 'the entire mucosa is beset

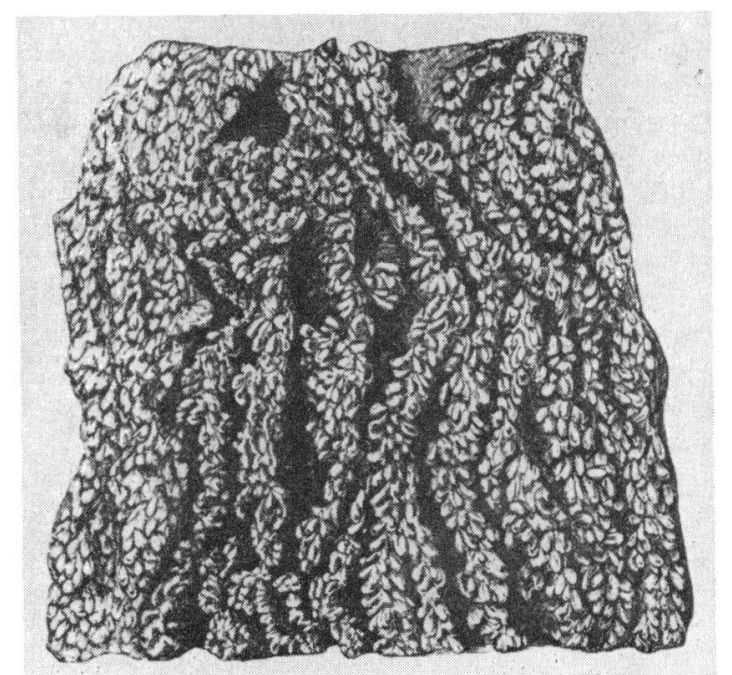

FIG. 1. Drawing to show papillation of duodenal mucosa (Reproduced from Trans. Path. Soc. London, 1895). 


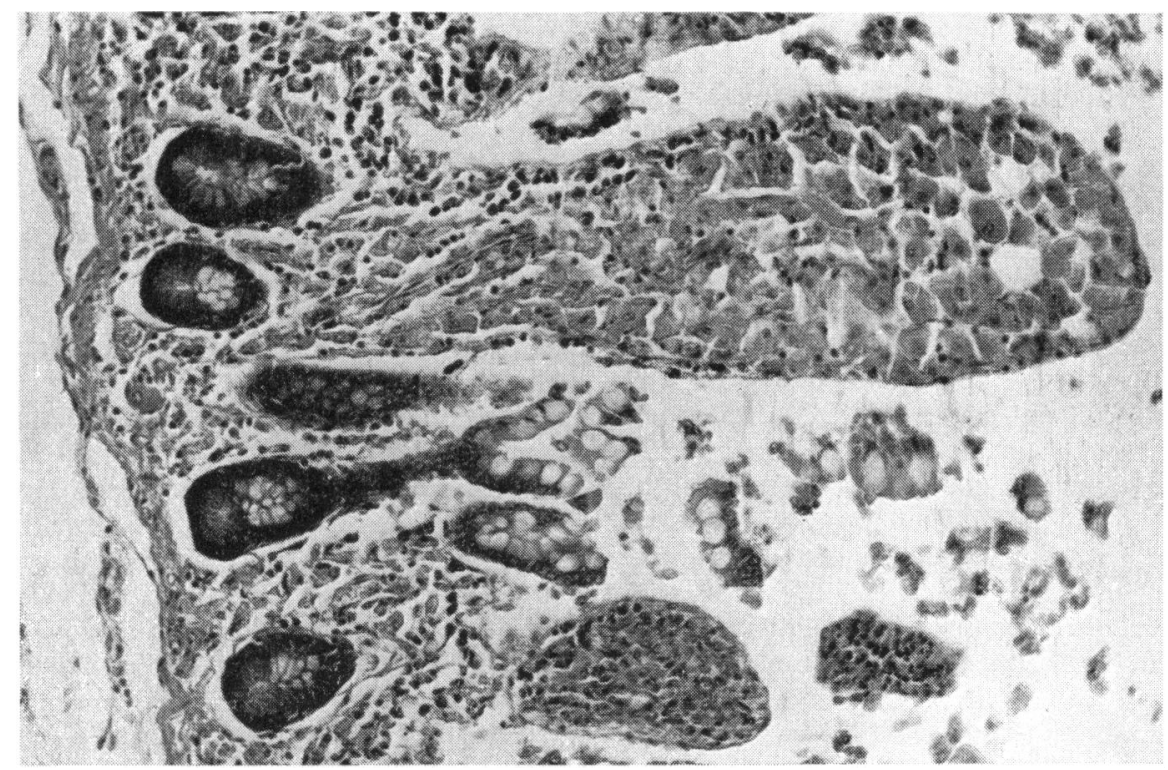

FIG. 2. Section of duodenal mucosa from a known case of Whipple's disease. Note the papillae formed by macrophages with foamy cytoplasm and small fat spaces. Haematoxylin and eosin $\times 125$.

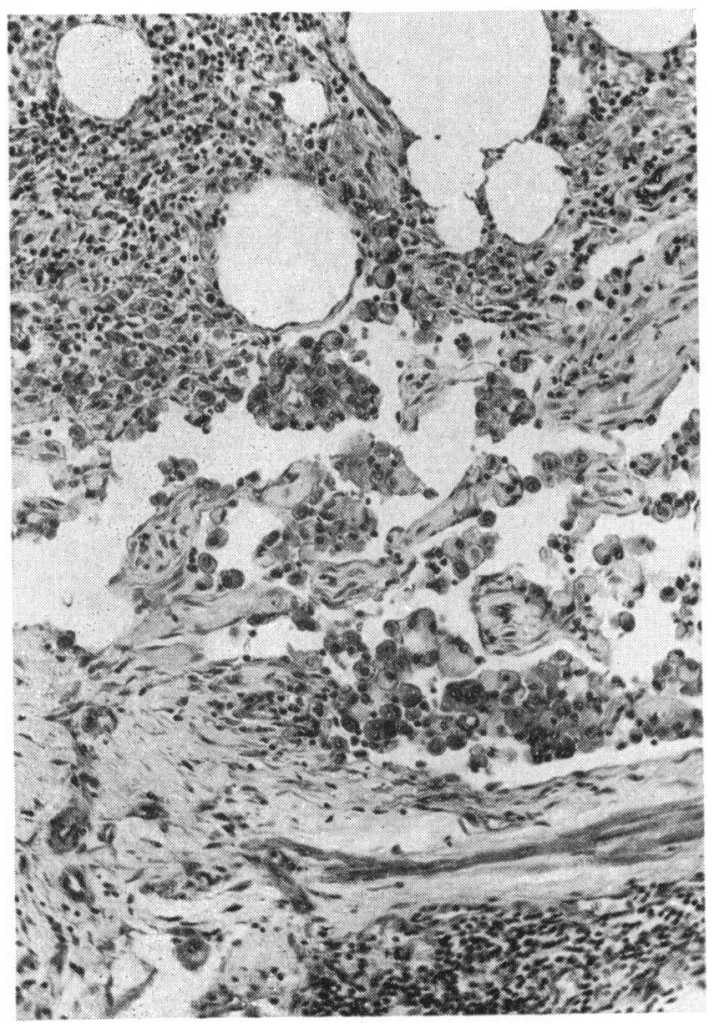

FIG. 3. Mesenteric lymph node from Christie's case showing lymphatics distended with fat (dissolved out in section) and foamy macrophages in peripheral sinuses. Haematoxylin and eosin $\times 125$.

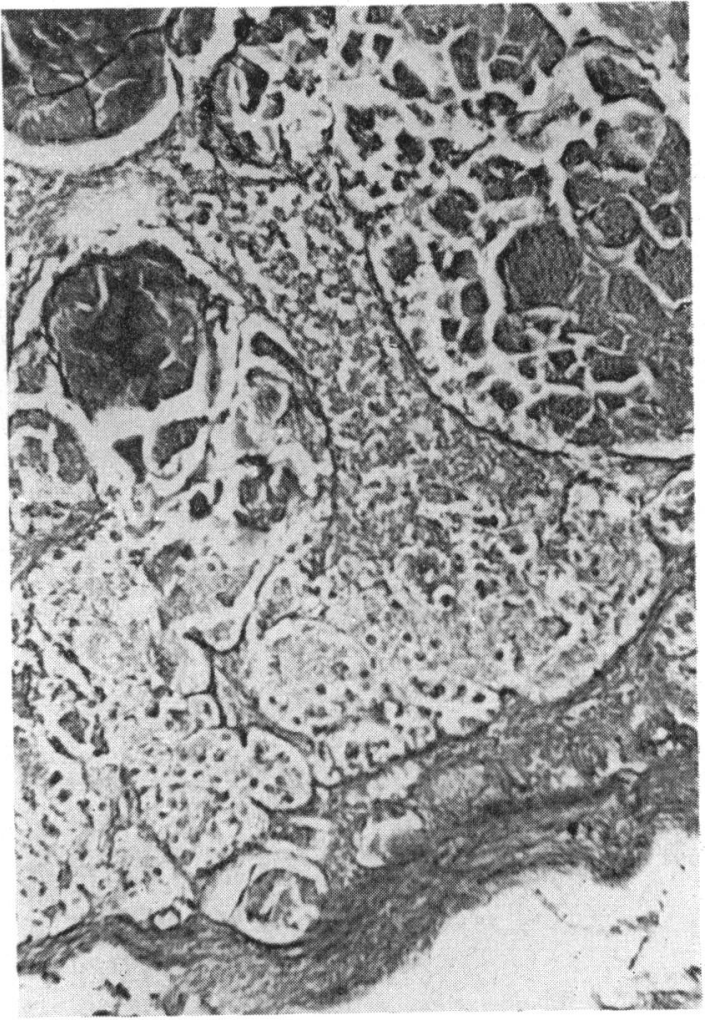

FIG. 4. Lymph node from Allchin and Hebb's case showing broken-down macrophages in the peripheral sinuses (cf. Fig. 3) and darkly staining mucopolysaccharides in the dilated lymphatics. $P A S \times 125$. 
with myriads of whitish flocculi, which give it a shaggy, coarsely villous appearance'. This they illustrated with a black and white drawing (Fig. 1). The disease process was sharply limited to the small intestine, the stomach and colon being normal. It was further noted that the intestinal contents were fluid, not offensive, 'and deposited on standing a considerable whitish sediment, which on microscopical examination was found to consist chiefly of oil globules, debris, and cells'.

The mesenteric lymph nodes were 'much enlarged, tough, yet flabby' and white dilated lacteals were seen passing along the mesentery from the intestine to the glands. Beyond the glands there was 'no discoverable affection of the lymphatic system'. All the other abdominal and thoracic viscera were normal.

Histology of the intestine showed dilatation of the lymphatic vessels, the lacteals of the villi being 'distended with an amorphous, finely granular substance containing a few cells. This material only gives a slight reaction with osmic acid'. Similar appearances were noted in the lymphatics of the mesenteric nodes. All these features are illustrated by coloured drawings. The authors conclude with these words: 'The appearances seen in the villi, the lacteal vessels, and mesenteric glands, together with the absence of any apparent lesion in the lymphatic system beyond the glands, suggest a varicosity of the vessels from obstruction, but the nature and cause of the obstruction is quite obscure'.

The case was presented to the Pathological Society on 21 May 1895.

Figures 2 and 3 are photomicographs of a known case of Whipple's disease prepared from sections presented to me by Dr. A. G. Christie (Christie and Galton, 1952). They show the typical fatty globules and PAS-positive macrophages in the duodenal villi and mesenteric lymph nodes. Figure 4 is a section of lymph node prepared this year from the specimen in the Westminster museum. Despite the deterioration in cytology, the similarity to Fig. 3 is obvious, and it is interesting to note that the PAS reaction for mucopolysaccharides is strongly positive after a lapse of 66 years.

Does the fact that Whipple was anticipated in the description of his disease mean that we should henceforth call it 'Allchin's disease?' Similar claims have been made in the case of other maladies with eponymous titles, e.g., Sjögren's disease, Reiter's disease, and no doubt many others-but without success. Allchin and Hebb's account is admirable in its conciseness, but that of Whipple runs to 19 columns of small print. He was not merely recording a curiosity; he was documenting for posterity, as fully as possible, a disease he believed (rightly) to be very rare and (wrongly) hitherto undescribed. It will go on being known as Whipple's disease, and we can take satisfaction in the thought that the first case to be recorded-in English at least-was described in a British journal.

I have to thank the Editor of the Broad Way, the organ of the students of Westminster Hospital, for permission to reproduce this article, which was originally published in the clinical supplement of March 1961.

\section{REFERENCES}

Allchin, W. H., and Hebb, R. G. (1895). Lymphangiectasis intestini. Trans. Path. Soc. Lond., 46, 221-223.

Christie, A. C., and Galton, D. A. G. (1952). A fatal case of intestinal lipodystrophy of Whipple investigated during life. J. Path. Bact., 64, 351-366.

Glynn, L. E., and Rosenheim, M. L. (1938). Mesenteric chyladenectasis with steatorrhoea and features of Addison's disease. Ibid., 47, 285-290.

Whipple, G. H. (1907). A hitherto undescribed disease characterized anatomically by deposits of fat and fatty acids in the intestinal and mesenteric lymphatic tissues. Johns Hopk. Hosp. Bull., 18, 382-391. 